Natalia M. Syssoeva, Irkutsk Scientific Center of SB RAS, Russia

Pavel A. SAdOVSKY

Institute of Geography SB RAS, Irkutsk, Russia

\title{
The impact of crisis on spatial structure of the Network Company
}

The basic principles of the organization of production are changing with the development of market relations in Russia. The management structures in many soviet and post-soviet enterprises were built in accordance with the rules of management worked out in the early twentieth century. The organizational structure, constructed in accordance with these rules, was called a hierarchical or bureaucratic structure.

The development of customization and other processes in production resulted in complication of these structures. Increasing number of network organizations was observed in the eighties, when international competition and rapid technological changes caused a large-scale restructuring in all sectors. Increased instability and strong competition for markets, the need to change the generations of products fast enough as well as information and computer revolution led to further search for effective forms of organizational structures to respond adequately to changing external environment. The network organization was one of the responses to these conditions.

Network organization is characterized by market relations between the main sections and links, ranging from supply of raw materials to sale of finished products. The main characteristics of such an organization are: flexibility, adaptability and an effective use of innovations. The units of these organizations also enjoy a high degree of autonomy. On the one hand, there is a beneficial ground for the development of more effective networks from supply to sale, but on the other hand the links in the network are less reliable.

As a rule the network of links in a large company has a geographical expression or projection and this specific form of spatial pattern of industry has a particular response to external shocks like the economic crisis.

The process of transformation of a network organization in crisis is shown on the example of a producer and distributor of construction materials in Russia - the Ingri company. It was established in 2006 as a regional promoter of Russian company TopHausBeton, the largest supplier of cement and polymer materials for construction of industrial floors. A network of inter-regional production and trade connections as well as new technologies introduction should cover the whole territory of Russia.

Production and sales of building materials for industrial enterprises are closely linked to investment activity in different regions. The management of the company is located in Moscow, it performs the interaction between distributors and suppliers as well as its own 
production enterprises (which are located in the cities of St. Petersburg and Yekaterinburg). It also provides uninterrupted operations of regional offices and regional representatives. The regional headquarters of the company are located in the largest cities of Russia and neighboring countries (fig. 1). The company has also started cooperation with the international concern BASF and the Swiss company Sika, delivering the best known brands and recent developments into the Russian market of industrial floors.

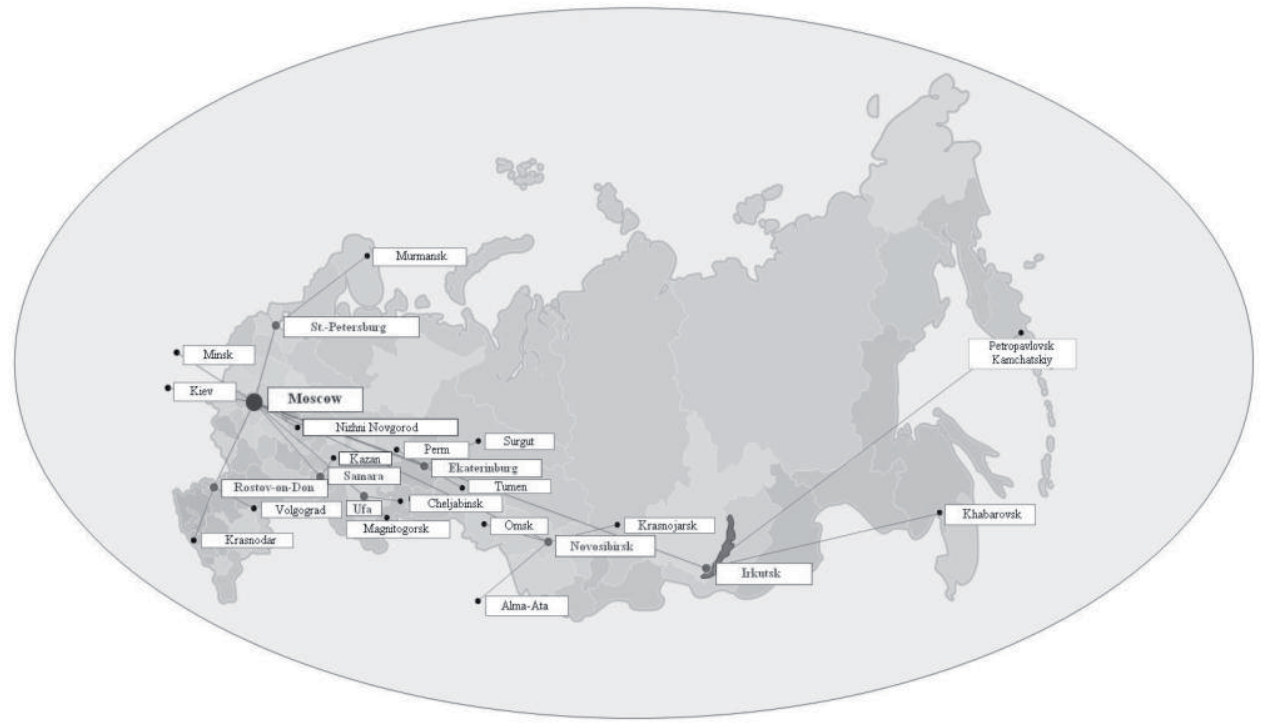

Fig. 1. The scheme of an arrangement of the basic links of the company

The regional level is a major part of the network where investments in industry and other manufacturing take place. Due to this a system of basic regions was developed, where the establishment of missions would give the greatest results. Irkutsk region is a major industrial area. Electricity, aluminum, various electrical and heating equipment, chemical and petrochemical products are all produced there. It is also known for timber harvesting and processing. The scheme of Ingri's links in the region is based on the major investment activity centers.

The global financial crisis has exerted a significant impact on investments, construction and consequently on enterprises producing construction materials. The dynamics of regional sales of the company in this period are shown in fig. 2. According to the statistics, in years 2008-2009 the manufacturing of concrete products decreased in Russia by $52 \%$, cement by $30 \%$ and bricks - by $47 \%$. At the same time, the prices of these products have fallen by more than 19\% (www.sk-info.ru, 2010). Simultaneously a decrease in company's activity was directly proportional to the reduction of investment and construction rates. 


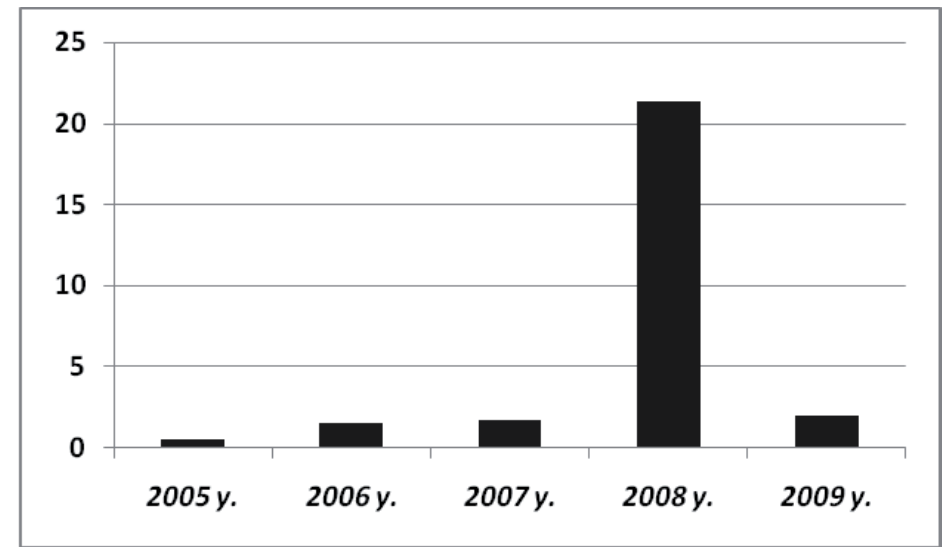

Fig. 2. The dynamics of Ingri's sales in Irkutsk region

After several months of existence in the new economic conditions, it became apparent that the company is unable to maintain its network. The result was the closure of local offices in Novosibirsk, Irkutsk, Ufa and Samara, as well as significant reductions of staff in central offices. In only few months, the company's personnel has declined more than ten times.

However, the construction as an industry has not disappeared in the crisis completely, and redistribution of the major players in this market has taken place. Former employees found themselves without work, but with the experience and accumulated base of customers and suppliers.

The rupture of a single all-russian structure led to formation of separate regional companies. The destruction of production networks began to restore due to social networks developed during the previous period. At the period of crisis seven new organizations emerged in Irkutsk region, united by a common client base, similar products and a single social network, based on former employees of Ingri. These companies form the connections with the suppliers beyond the parent company and are able to diversify the scope of partners (fig. 3). Similar processes took place in other regions where regional offices of Ingri were closed.

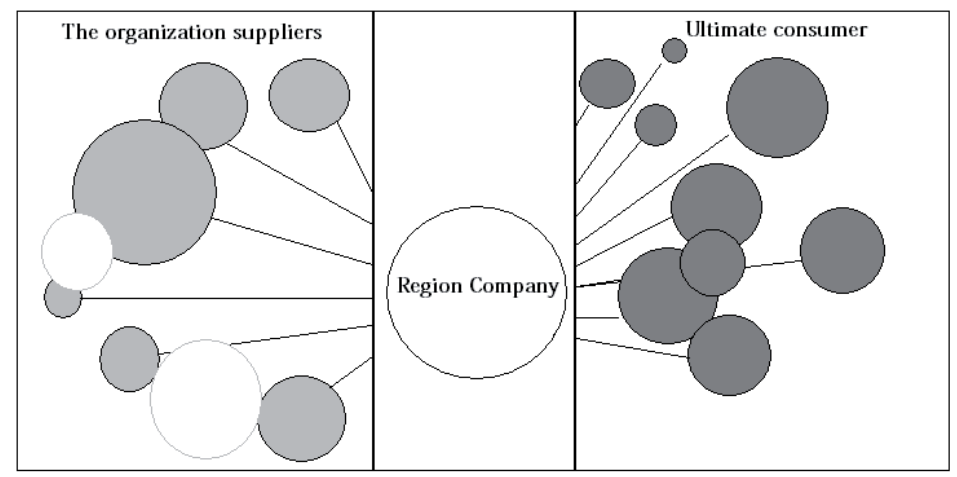

Fig. 3. The scheme of contacts of a regional company 
Is it a positive or a negative process?

The first visible result is strengthening of competition in regions. The second result - diversification and fall of prices of products and services. Before the crisis the parent company kept a stable pricing policy for a long time and all regional offices maintained the system. Currently, dumping the prices is a common event in the market.

The other consequences will follow. Some of the small firms do not work out long-term strategies, do not monitor the development of new technologies and do not implement all project requirements. The last circumstance is the most serious since it brings the loss of credit to all associations of firms.

The need for a coherent policy for overall survival leads to the formation of industrial clusters. In the case of Irkutsk region, the cluster is formed around several centers of Ingri and includes a number of smaller domestic companies, which established and even strengthened their position in the crisis. They have to coordinate their policy, maintain the level of quality and the internal competition forces them to introduce innovations. Almost monopolistic structure of the previous regional spatial pattern has given way to a more flexible system of companies formed on the Ingri's social network.

The formation of a unified policy within the region allows for interaction between the regional companies or their associations. Regional companies have divided the markets of the former parent structure. For example, the companies of Irkutsk region work with customers of Chita region, Buryatia and Yakutia.

Such a cluster of small and medium firms is able to attract resources and products from different manufacturers, and the presence of internal competition may lead in turn to lower prices and improvement of product quality. Today most manufacturers refuse to create their own networks and promote their products actively through the post-ingri network.

The parent company actually begins a network recovery at the federal level, with the difference, that the role of connection designer now comes to regional companies. The parent company does not restore its representatives in the regions, it passes the rights to distribute its products to regional firms.

The crisis has seriously influenced the spatial pattern of a given network company. This case affirmed one of the negative aspects of network organization mentioned above - that is low reliability of internal links. Yet, it gave a rise to new patterns where advantages of network relations that include: flexibility, adaptability to new demand, new technology and other conditions, are strengthened. The process of cluster formation in regions like Irkutsk where large business has always been a predominant form of production is not rapid and easy, but it takes place.

\section{References}

Retrieved 5.12.2010 from www.sk-info.ru 


\section{The impact of crisis on spatial structure of the Network Company}

The paper presents changes in the spatial relationships between the agents of the network company in times of crisis. The analyzed company performs the production and supply of cement-based and polymer materials for industrial construction and has offices in the most industrialized regions of Russia. In crisis the company decided to withdraw from certain markets and closed some regional missions. The rupture of a unitary structure of the company led to formation of separate regional firms. On the basis of the parent company new organizations have been formed in some regions united by a common client base, similar products and a unified social network. This process has both positive and negative aspects for customers and manufacturers. The need for policy coherence for the overall survival results in the formation of a new regional industry clusters with the intention of improving product and service quality.

Prof. Natalia M. Syssoeva, doctor of geographical sciences

Siberian Branch of Russiam Academs of Sciences

Irkutsk Scientific Center of SB RAS

e-mail: syssoeva@orespirk.ru.

Mgr Pavel A. Sadovsky

the post-graduate of the Institute of Geography of SB RAS 